\title{
Evaluation of Physical-Chemical and Microbiological Stability of Fluconazole Oral Suspensions for Hospital Use
}

\author{
Camilo M. D’Amore*a, Elisa de S. Simon ${ }^{a}$, Martin Steppe ${ }^{\mathrm{a}}$ \\ ${ }^{a}$ Laboratório de Controle de Qualidade Farmacêutico, Faculdade de Farmácia, Universidade Federal do Rio Grande do \\ Sul, Porto Alegre, Brasil. \\ *Corresponding author: camilodamore@hotmail.com
}

Fluconazole is an important drug in the treatment of cutaneous and systemic mycoses. The Hospital de Clínicas de Porto Alegre performs a derivation of fluconazole capsules to obtain an oral liquid formulation that is easily administered and whose dose can be adjusted. In order to replace the derivation for a formulation produced from an active pharmaceutical ingredient, this study sought to develop a liquid oral formulation, evaluate its physical chemical and microbiological stability and demonstrate suitability of the analytical method for the formulation assay. Seven different formulations of pharmaceutical suspension form were produced and evaluated for $\mathrm{pH}$, viscosity, sedimentation volume and assay. The analytical method by High Performance Liquid Chromatography was demonstrated. Two most promising formulations were manipulated in the Farmácia Semi-Industrial do Hospital de Clínicas de Porto Alegre and stored in amber PET bottles under three different conditions: room temperature, under refrigeration $\left(2\right.$ to $\left.8{ }^{\circ} \mathrm{C}\right)$ and in an oven $\left(40^{\circ} \mathrm{C}\right)$. Samples were collected after 0,7 and 14 days to evaluate physical-chemical stability, assay, pH and macroscopic aspects. Samples were collected after 0 and 21 days to evaluate microbiological stability. It was possible to demonstrate stability for one of the formulations for a 14-day period. Throughout the study, the chosen formulation presented adequate quantification of fluconazole, constant $\mathrm{pH}$, no organoleptic changes and no microbial growth. The results suggest the incorporation of a new formulation for fluconazole to the Farmacia Semi-Industrial portfolio).

Keywords: Fluconazole. Analytical Method Suitability. Formulation Development. Formulation Stability.

DOI: https://doi.org/10.22456/2527-2616.103473

\section{Introduction}

Fluconazole is a triazole antifungal drug, one of the most important drug classes used in cutaneous and systemic mycoses treatment ${ }^{1}$. Triazoles act by inhibiting ergosterol synthesis, an important fungal cell membrane component. Fluconazole has a broad spectrum of activity and is used to treat infections like candidiasis and cryptococcal meningitis. It is especially useful in transplanted patients' prophylactic treatment and to fight infections in immunosuppressed patients 2, 3, 4, 5, 6 .

The Hospital de Clínicas de Porto Alegre has many patients with needs for specific medications, such as pediatric patients, transplanted patients and patients using catheters, drains and tubes. To treat those cases, the Farmácia SemiIndustrial (FSI) performs manipulations or pharmaceutical derivations. Formulation stability studies are necessary to look at the best way of preparation, the package to be used, storage conditions and expiration date. ${ }^{7,8}$. Fluconazole oral suspension is among the FSI's products.

Most of the medications are available in solid dosage form, which is not the most appropriate form to be considered for patients with specific administration and dosage needs (pediatric and transplanted patients, for example) ${ }^{9,10}$. One alternative is the oral administration of parenteral formulations, but their concentrations demand dilution and manipulation, which can make de final volume unfeasible for oral administration ${ }^{11,12}$. This can be solved by preparing oral solutions or suspensions from solid forms or even from the active pharmaceutical ingredient itself ${ }^{13}$. In order to facilitate the administration of fluconazole to patients admitted to the hospital, the present study sought to prepare a fluconazole liquid oral formulation, in the pharmaceutical suspension form. We also attempted to verify the suitability of a compendial analytical method for the quantitative determination of fluconazole in the developed suspension and to evaluate its physical-chemical and microbiological stability to propose a safe time interval for its use.

\section{Materials and methods}

Reagents: Purified water, Direct-Q3UV, Millipore®; Potassium phosphate monobasic, Merck®; Methanol for liquid chromatography, LiChrpsolv®; Acetonitrile for liquid chromatography, Vetec ®; Fluconazole standard substance, declared content of $100.9 \%$ (LAPPS-Faculdade de Farmácia/UFRGS)

Pharmaceutical ingredients: Fluconazole active pharmaceutical ingredient, Delaware $\AA$, declared content of 99.68\%, Batch 1007/17; Carboxymethylcellulose, Delaware ®, batch 1006/16; Simple Syrup, FSI/HCPA, Batch 002/18; Glycerin, Rioquímica ®, Batch 1701655; Propyleneglycol, Rioquímica ®, Batch 1512043.

\section{Formulation Development}

Seven fluconazole suspensions of $50 \mathrm{mg} / \mathrm{mL}$ were manipulated and evaluated for $\mathrm{pH}$, viscosity and sedimentation volume. The composition for each formulation is shown in Table 1. For all formulations, fluconazole was previously ground in a mortar and levigated with glycerin or propyleneglycol. HANNA Instruments $\mathrm{pH} 21$ model $\mathrm{pH}$ meter was used to determinate the $\mathrm{pH}$ of the formulations. Viscosity was measured using a model RDVD-1 + Brookfield Viscosimeter with a $\mathrm{n}^{\mathrm{o}} 4$ spindle at $100 \mathrm{rpm}$. The sedimentation volume was calculated (Equation 1) and the volume of formed sediment was measured in a graduated cylinder 1, 2, 24, 48, 72 and 168 hours after resuspension. 


$$
\text { Sedimentation Volume }=\frac{\text { Sediment Volume }(m L)}{\text { Total Volume }(m L)} \quad \boldsymbol{E} \boldsymbol{q}(\mathbf{1})
$$

Table 1 -Fluconazole suspensions content.

\begin{tabular}{cccccc}
\hline Formulation & Fluconazole & Glycerin & PPG $^{\mathbf{1}}$ & CMC $^{2}$ & $\begin{array}{c}\text { Simple } \\
\text { Syrup }\end{array}$ \\
\hline 1 & $5 \mathrm{~g}$ & - & - & - & $\mathrm{qs} 100 \mathrm{~mL}$ \\
2 & $5 \mathrm{~g}$ & $10 \mathrm{~mL}$ & - & - & $\mathrm{qs} 100 \mathrm{~mL}$ \\
3 & $5 \mathrm{~g}$ & - & $10 \mathrm{~mL}$ & - & $\mathrm{qs} 100 \mathrm{~mL}$ \\
4 & $5 \mathrm{~g}$ & $10 \mathrm{~mL}$ & - & $\mathrm{qs} 100 \mathrm{~mL}$ & - \\
5 & $5 \mathrm{~g}$ & $10 \mathrm{~mL}$ & - & $40 \mathrm{~mL}$ & $\mathrm{qs} 100 \mathrm{~mL}$ \\
6 & $5 \mathrm{~g}$ & $10 \mathrm{~mL}$ & - & $25 \mathrm{~mL}$ & $\mathrm{qs} 100 \mathrm{~mL}$ \\
7 & $5 \mathrm{~g}$ & $10 \mathrm{~mL}$ & - & $10 \mathrm{~mL}$ & $\mathrm{qs} 100 \mathrm{~mL}$ \\
\hline
\end{tabular}

${ }^{1}$ Propyleneglycol, ${ }^{2}$ Carboxymethylcellulose, $1 \%$ aqueous solution.

\section{Analytical Method Suitability}

The compendial method for fluconazole assay in suspension recommended by the United States Pharmacopeia 41th edition ${ }^{14}$ was used to evaluate the the quantitative content of the formulations. Samples were analyzed on an Agilent High Efficiency Liquid Chromatograph, LC 1200 series, equipped with quaternary pump (G1311A), autoinjector (G1329A) and diode array detector (1315B), using a Zorbax Eclipse Plus C18 Agilent $®$ chromatographic column $(150 \mathrm{~mm} \times 4.6 \mathrm{~mm} x$ $5 \mu \mathrm{m}$ ). ChemStation software version B03.02 was used for data acquisition and analysis of results. The suitability of the method was demonstrated by evaluating the following parameters.

Selectivity: The chromatograms of Formulation 6 (which contains all evaluated excipients) were compared to those of a placebo formulation with no active ingredient.

Linearity: $1 \mathrm{mg} / \mathrm{mL}$ fluconazole standard stock solution was prepared and diluted to reach fluconazole final concentrations of $80,90,100,110$ and $120 \mu \mathrm{g} / \mathrm{mL}$. This procedure was repeated three times independently.

Precision: Six fluconazole sample solutions at $100 \mu \mathrm{g} / \mathrm{mL}$ concentration were prepared. DPR of the six samples was used to determine Repeatability. DPR among twelve samples prepared on different days by different analysts was used to determine intermediate precision.

Accuracy: 100, 110 and $120 \mu \mathrm{g} / \mathrm{mL}$ fluconazole solutions were obtained by adding different amounts of $1 \mathrm{mg} / \mathrm{mL}$ fluconazole standard solution in $1 \mathrm{mg} / \mathrm{mL}$ fluconazole sample solution. Accuracy was assessed by the recovery in each concentration in triplicate.

\section{Stability Study}

The formulations that showed previous results within limits established internally were produced on a semi-industrial scale and placed in amber PET bottles for the stability study. A sample was taken to perform a microbiological test. Five bottles of each formulation were stored at room temperature, in a refrigerator $\left(2\right.$ to $\left.8^{\circ} \mathrm{C}\right)$ and in an oven $\left(40^{\circ} \mathrm{C}\right)$. Three of these bottles were used for the HPLC assay, one bottle was used for $\mathrm{pH}$ and macroscopic analyses and the last one for the microbiological assay.

\section{Microbiological Assay}

Samples were sent to an outsourced lab (GRAM - Laboratório de Análises Microbiológicas Ltda) at 0 and 21 days of storage. An assay for Pseudomonas aeruginosa, Staphylococcus aureus, Escherichia coli and Salmonella spp. was performed by the Cultural Method described in the Bacteriological Analytical Manual (2001) - Food and Drug Administration. Counts of total aerobic bacteria and total molds and yeasts were performed using the Pour Plate method described in Farmacopeia Brasileira, 5th Edition.

\section{Results and Discussion}

\section{Formulation Development}

Formulation 1, which consisted of fluconazole incorporated into syrup, developed aggregates after manipulation. Levigating the drug with glycerin prior to the incorporation in Formulation 2 solved that problem. When using propylene glycol to replace glycerin in Formulation 3, levigation proved to be difficult and inefficient. The use of a $1 \%$ aqueous solution of carboxymethylcellulose (CMC) as a vehicle instead of syrup (Formulation 4) impaired fluconazole incorporation due to high viscosity, which led to the development of lumps in the formulation. Different quantities of $1 \%$ CMC solution were then tested (Formulations 5, 6 and 7). All of them were easily prepared and demonstrated good appearance, free of lumps or air bubbles.

\section{pH and Viscosity}

Table 2 describes the $\mathrm{pH}$ and viscosity results obtained for the seven formulations tested. Formulation 2 had the lowest $\mathrm{pH}$ value of 5.78, and the highest recorded value was 6.82 for Formulation 4. The viscosity analysis indicated that formulations containing only simple syrup as a vehicle were the most fluid. The viscosity and torque values increase as the amount of $\mathrm{CMC}$ in the formulation increases. It is desirable that suspensions have a suitable viscosity to keep solid particles dispersed, ensuring homogeneity and dose uniformity. On the other hand, very viscous formulations should be avoided when it comes to the administration of the drug, as drug dispersion becomes difficult and the product can be partially retained in measuring cups, syringes and tubes ${ }^{15}$.

Table 2 - $p H$, viscosity and torque values for the formulations manipulated.

\begin{tabular}{cccc}
\hline Formulation & $\mathbf{p H}^{\mathbf{1}}$ & Viscosity $(\mathbf{c P})$ & Torque (\%) \\
\hline 1 & $6.24( \pm 0.04)$ & 259 & 13.0 \\
2 & $5.78( \pm 0.02)$ & 356 & 13.9 \\
4 & $6.82( \pm 0.07)$ & 1437 & 71.8 \\
5 & $6.36( \pm 0.03)$ & 1024 & 51.2 \\
6 & $6.18( \pm 0.03)$ & 906 & 45.5 \\
7 & $6.30( \pm 0.13)$ & 422 & 19.3 \\
\hline
\end{tabular}

${ }^{1}$ Mean and standard deviation for triplicates. 
Drug Anal. Res., v. 4, n. 1, p. 39-43, 2020

Volume of Sedimentation

Table 3 describes the results obtained for the sedimentation volume for the seven formulations tested. Formulations 1 and 2 , which only had simple syrup as a vehicle, presented the highest sediment volumes and the highest sedimentation speeds. The inclusion of CMC in the formulations delayed this process. The use of a mixture of simple syrup and CMC as a vehicle proved to be more promising in Formulations 5, 6 and 7, with minimal sedimentation over 7 days. The volume of sedimentation obtained was proportionally higher to the quantity of CMC in the formulation.

Stokes' Law dictates that a particle rate of sedimentation is directly proportional to its diameter and inversely proportional to the medium viscosity ${ }^{14}$. Grinding the drug prior to manipulation aims to reduce and normalize its particle size, leaving the medium viscosity as the only variable that affects sedimentation. The results obtained from the viscosity corroborate those from sedimentation volume, since the volumes tend to be proportionally higher to the viscosity of the formulations.

Table 3 - Sedimentation volume calculated through the sediment volumes formed in each formulation over a 7-day follow-up.

\begin{tabular}{|c|c|c|c|c|c|c|}
\hline \multicolumn{7}{|c|}{ Volume of Sedimentation } \\
\hline \multirow{2}{*}{ Time } & \multicolumn{6}{|c|}{$\begin{array}{ll}\text { Formulation } \\
\end{array}$} \\
\hline & 1 & 2 & 4 & 5 & 6 & 7 \\
\hline $\mathrm{Oh}$ & 1.00 & 1.00 & 1.00 & 1.00 & 1.00 & 1.00 \\
\hline $1 \mathrm{~h}$ & 1.00 & 1.00 & 1.00 & 1.00 & 1.00 & 1.00 \\
\hline $2 \mathrm{~h}$ & 1.00 & 1.00 & 0.98 & 1.00 & 1.00 & 1.00 \\
\hline $24 \mathrm{~h}$ & 0.29 & 0.78 & 0.94 & 0.97 & 0.97 & 0.97 \\
\hline $48 \mathrm{~h}$ & 0.29 & 0.66 & 0.89 & 0.97 & 0.95 & 0.94 \\
\hline $72 \mathrm{~h}$ & 0.29 & 0.58 & 0.84 & 0.97 & 0.94 & 0.91 \\
\hline $168 \mathrm{~h}$ & 0.29 & 0.50 & 0.60 & 0.94 & 0.87 & 0.85 \\
\hline
\end{tabular}

\section{Stability Study}

A pH close to neutrality was sought in formulations tested since this is more desirable for oral administration and because fluconazole degradation products were previously detected at extreme $\mathrm{pH}$ values ${ }^{6}$. A high viscosity value was not desired because it would make the administration with syringes and tubes difficult. The formulation also needs to keep its particles in suspension for as long as possible, ensuring the particles would not tend to compact, making the redispersion process easier. Thus, Formulations 6 and 7 were selected to continue the stability study.

The formulation quantification assay results performed over 14 days under different storage conditions are shown in Table 4. The profiles can be analyzed in Figure 1. Fluconazole content was depleted by $8.5 \%, 12.5 \%$ and $11.5 \%$ in Formulation 6 at the end of 14 days when stored at room temperature, under refrigeration and in an oven at $40{ }^{\circ} \mathrm{C}$, respectively. In Formulation 7, the reduction of content was $3.4 \%$ for room temperature storage, $5.6 \%$ under refrigeration and $6.5 \%$ for oven storage. Both formulations remained above $90 \%$ of content during the stability study. After 14 days, Formulation 6 presented equivalent results when stored under refrigeration and in an oven, since there is no statistically significant difference between these conditions
(P> 0.05). When stored at room temperature, a smaller loss of content was observed, indicating greater stability. When Formulation 7 is stored in an oven, an increase in content is noticed between days 7 and 14. This may be due to loss of water by evaporation, resulting in formulation concentration.

The $\mathrm{pH}$ of the formulations was also evaluated along with the assay. Table 5 shows the $\mathrm{pH}$ values over time. Although both formulations have differences in composition and have been subjected to three storage temperatures, the $\mathrm{pH}$ presented little variation in all samples, remaining stable throughout the study. Both formulations showed the same profile in all cases, with a small drop in $\mathrm{pH}$ on the 7 th day, returning to values close to the original on the 14 th day.

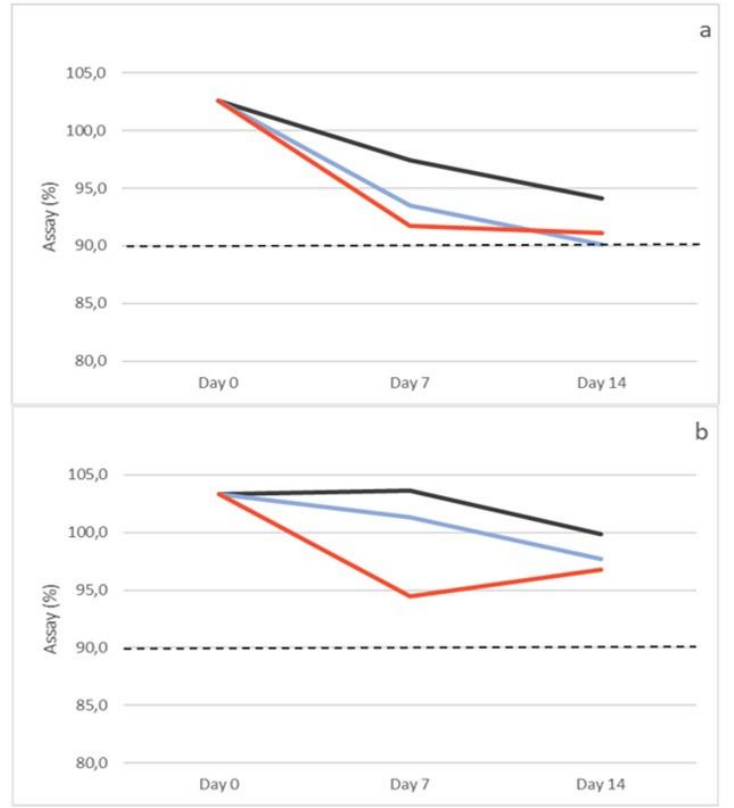

Figure 1 - Graphical representation of assay results in the stability study for Formulations $6(a)$ and 7 (b). In black, bottles stored at room temperature. In blue, bottles stored under refrigeration $\left(2-8^{\circ} \mathrm{C}\right)$. In red, bottles stored in an oven $\left(40{ }^{\circ} \mathrm{C}\right)$.

Throughout the study, Formulation 6 showed no change in organoleptic properties. However, Formulation 7 showed a slightly darker color and phase separation under all storage conditions on the 14th day of stability (Figure 2). Since the only difference between the formulations is CMC proportion, it is assumed that the quantity used in Formulation 7 was insufficient to keep fluconazole in suspension, causing phase separation. Therefore, formulation 7 is not recommended for use due to the results obtained during the stability study.

Both formulations presented absence of pathogens used in control and low aerobic bacteria, molds and total yeasts counts under all storage conditions after 0 and 21 days of manipulation. The evaluation of microbiological stability is used to determine a safe interval for product consumption, demonstrating storage conditions and product ability to avoid harmful effects from microbial contamination ${ }^{9}$ 
Drug Anal. Res., v. 4, n. 1, p. 39-43, 2020

Table 4 - Formulation assay results throughout 14 days of stability study when stored at room temperature, under refrigeration $\left(2^{\circ} \mathrm{C}-8^{\circ} \mathrm{C}\right)$ and in an oven $\left(40^{\circ} \mathrm{C}\right)$.

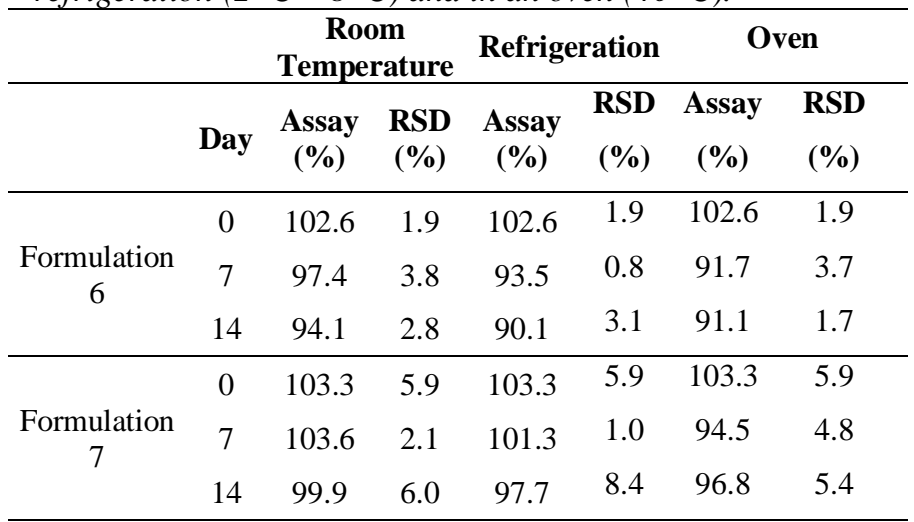

Table 5 -Formulation $p H$ results throughout 14 days of stability study when stored at room temperature, under refrigeration $\left(2^{\circ} \mathrm{C}-8{ }^{\circ} \mathrm{C}\right)$ and in an oven $\left(40^{\circ} \mathrm{C}\right)$.

\begin{tabular}{ccccc}
\hline \multicolumn{5}{c}{$\mathbf{p H}$} \\
& Day & $\begin{array}{c}\text { Room } \\
\text { Temperature }\end{array}$ & Refrigeration & Oven \\
\hline Formulation & 0 & 5.42 & 5.47 & 5.45 \\
6 & 7 & 4.55 & 4.57 & 4.34 \\
& 14 & 5.42 & 5.70 & 5.30 \\
\hline \multirow{2}{*}{ Formulation } & 0 & 5.45 & 5.47 & 5.42 \\
7 & 7 & 4.58 & 4.54 & 4.28 \\
& 14 & 5.66 & 5.84 & 5.42 \\
\hline
\end{tabular}

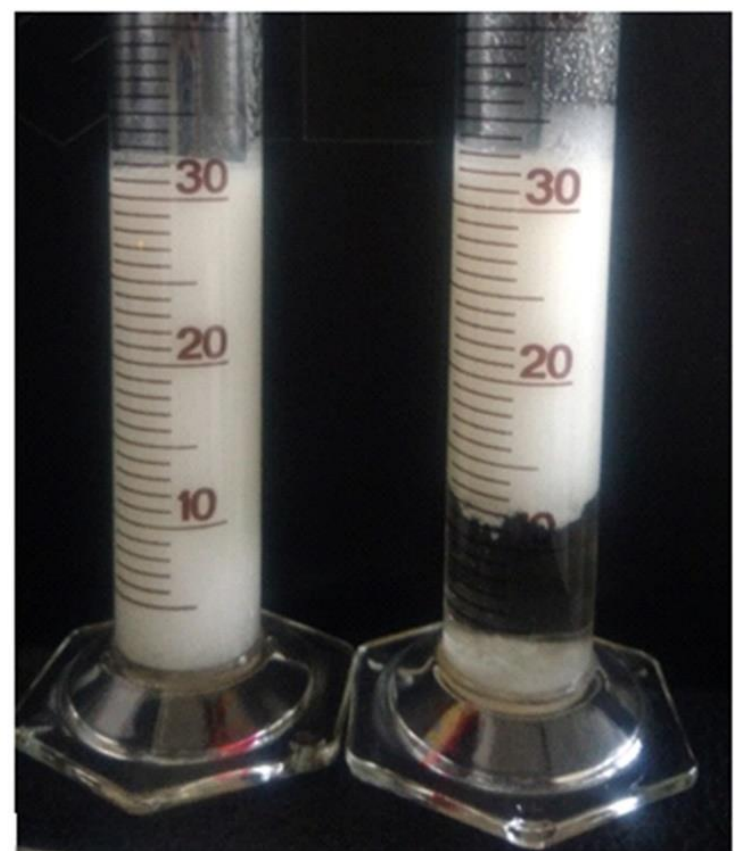

Figure 2 - Phase separation observed after 14 days of stability in Formulation 7 (right graduated cylinder). Formulation 6 after 14 days of stability for comparison (left graduated cylinder).
Analytical Method Suitability

Selectivity: Figure 3 shows Formulation 6 and placebo chromatograms. No interfering peak is observed in fluconazole retention time $(3.491 \mathrm{~min})$.

Linearity: Linear regression obtained provided the equation y $=4.2113 \mathrm{x}-26.105$ and a 0.9972 coefficient of determination (r2). Residue analysis demonstrated homoscedasticity, absence of outlier points and absence of trend in their variances, demonstrating a random distribution.

Precision: Based on criteria from the Association of Official Analytical Chemists (AOAC), the minimum relative standard deviation (RSD) required is $2.7 \%$ for repeatability and $4 \%$ for intermediate precision. In the present study, the RSD obtained were $0.54 \%$ and $1.46 \%$ respectively.

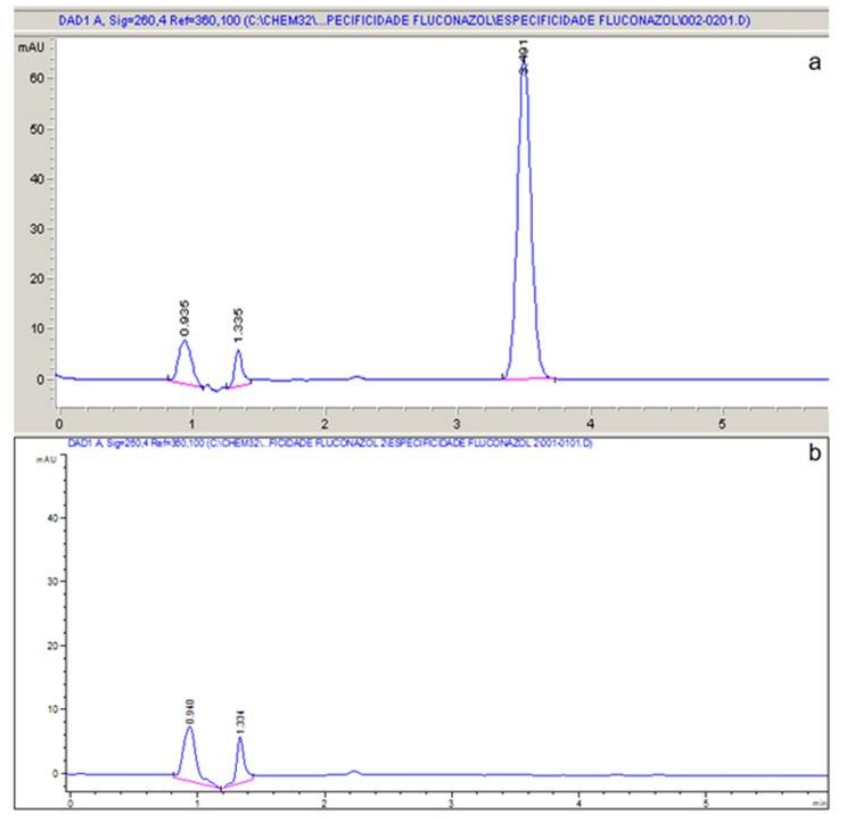

Figure 3 - Formulation 6 (a) and Placebo (b) chromatograms. Mobile phase composed of acetonitrile and monobasic potassium phosphate buffer $20 \mathrm{mM} \mathrm{pH} 2.5$ (80:20) at isocratic flow rate of $1.5 \mathrm{~mL} / \mathrm{min}$, injection volume of $50 \mu \mathrm{L}$, room temperature, $U V$ detector at $260 \mathrm{~nm}$, Zorbax Eclipse column Plus C18 Agilent ${ }^{\circledR}(150 \mathrm{~mm} \times 4.6 \mathrm{~mm} \times 5$ $\mu \mathrm{m})$.

Accuracy: Based on criteria of the Association of Official Analytical Chemists (AOAC), recovery should be in the range of $97 \%$ to $103 \%$. Table 6 shows recovery obtained and demonstrates method accuracy.

Table 6 - Standard solution recoveries from samples obtained during analytical method accuracy.

\begin{tabular}{cccc}
\hline \multicolumn{4}{c}{ Accuracy } \\
\hline $\begin{array}{c}\text { Level } \\
(\boldsymbol{\%})\end{array}$ & $\begin{array}{c}\text { Fluconazole } \\
\text { Concentration } \\
(\boldsymbol{\mu g} / \mathbf{m L})\end{array}$ & $\begin{array}{c}\text { Standard } \\
\text { Added }(\boldsymbol{\mu g})\end{array}$ & $\begin{array}{c}\text { Mean Recovery } \\
(\boldsymbol{\%})\end{array}$ \\
\hline 100 & 100 & 200 & 99.77 \\
110 & 110 & 300 & 102.64 \\
120 & 120 & 400 & 100.20 \\
\hline
\end{tabular}




\section{Conclusion}

It was possible to develop and characterize a liquid formulation for oral use in pharmaceutical suspension form containing fluconazole suitable for hospital use. It was also possible to demonstrate the suitability for a compendial assay method for the developed formulation.

Formulation 6 was the most appropriate for hospital use and its results suggest incorporation of the suspension into the Farmacia Semi-Industrial portfolio, with a recommended shelf life of 14 days, stored in amber PET bottles and at room temperature.

\section{Acknowledgments}

To the Farmácia Semi-Industrial at Hospital de Clínicas de Porto Alegre.

To the Laboratório de Controle de Qualidade Farmacêutico at Universidade Federal do Rio Grande do Sul.

\section{Conflict of interest}

None to declare.

\section{References}

1. Castro G, et al. Time-of-flight mass spectrometry assessment of fluconazole and climbazole UV and UV/H2O2 degradability: Kinetics study and transformation products elucidation. Water Research, 2015; 681-690.

2. Bourichia $\mathrm{H}$, et al. Solid-state characterization and impurities determination of fluconazol generic products marketed in Morocco. Journal of Pharmaceutical Analysis. 2012; 412-421.

3. Cyr TD, et al. Spectral characterization of fluconazole. Journal of Pharmaceutical and Biomedical Analysis. 1996; 247-255.

4. Dentinger PJ, Swenson, C. F. Stability of Reconstituted Fluconazole Oral Suspension in Plastic. The Annals of Pharmacotherapy. 2009; 285289.

5. Hurtado FK, et al. Microbiological Assay and HPLC Method for the Determination of Fluconazole in Pharmaceutical Injectable Formulations. Latin American Journal of Pharmacy. 2008; 224-228.

6. Sweetman, SC. Martindale: The Complete Drug Reference. 36. ed. London: Rps Publishing; 2009.

7. Ayers MV et al.. Evaluation of the stability of Vigabatrin in hospitalar extemporaneous formulations. Drug Analytical Research, 2019; 5160 .

8. BRASIL. Resolução RDC $\mathrm{n}^{\circ} 318$, de 06 de novembro de 2019. Estabelece os critérios para a realização de Estudos de Estabilidade de insumos farmacêuticos ativos e medicamentos, exceto biológicos, e dá outras providências. Diário Oficial União. 07 nov 2019.

9. Gobetti C. Avaliação da Estabilidade de Derivação Farmacêutica Hospitalar de Tizanidina. Porto Alegre: Universidade Federal do Rio Grande do Sul, 2017. Dissertação de Mestrado em Ciências Farmacêuticas.

10. Nahata MC, Loyd V, Allen J. Extemporaneous Drug Formulations. Clinical Therapeutics, 2008; 21122119.

11. Costa PQ, Lima JES, Coelho HLL. Prescrição e preparo de medicamentos sem formulação adequada para crianças: um estudo de base hospitalar. Brazilian Journal of Pharmaceutical Sciences, 2009; 57-66.

12. Peterlini MAS, Chaud MN, Pedreira MLG. Órfãos de terapia medicamentosa: a administração de medicamentos por via intravenosa em crianças hospitalizadas. Rev Latino-am Enfermagem, 2003; 11(1):88-95.

13. Giam JÁ, Mclachilan AJ. Extemporaneous product use in paediatric patients: a systematic review. International Journal of Pharmacy Practice, 2008; 3 10 .

14. USP 41. The United States Pharmacopeia. 41. ed. Rockville: United States Pharmacopeia Convention, 2017.

15. Allen LV, Popovich NG, Ansel HC. Ansel's Pharmaceutical Dosage Forms and Drug Delivery Systems. 9. ed. Philadelphia: Lippincott Williams \& Wilkins; 2011.

16. AOAC INTERNATIONAL, Guidelines for standard method performance requirements Appendix f. AOAC official methods of analysis, 2016. 